\title{
IDENTIDADE TERRITORIAL E MOVIMENTOS SOCIAIS NO BLOG "EU NA FLORESTA": UMA PERSPECTIVA GEOGRÁFICA
}

\author{
Karolini de Oliveira ${ }^{1}$
}

RESUMO: O presente trabalho tem como objetivo fazer uma breve discussão sobre identidade territorial e os movimentos sociais reproduzidos no blog "Eu na floresta: quem são e como vivem os povos da Amazônia". Escrito pela jornalista Maria Fernanda Ribeiro, o blog está hospedado no site do jornal Estadão desde 2016, quando a jornalista viajou ao Acre a fim de iniciar sua jornada pela Amazônia. As reflexões levantadas foram motivadas a partir de leitura sobre o tema e discussões feitas em sala de aula durante a disciplina de "Linguagem, Fronteira e Interculturalidade", no curso de mestrado do Programa de Pós-graduação Linguagem e Identidade - PPGLI, da Universidade Federal do Acre - UFAC. Dentre os autores estudados na disciplina, Rogério Haesbaert e Pablo Ortiz Tirado embasam o trabalho com diferentes conceitos sobre identidade territorial e movimentos sociais.

PALAVRAS-CHAVE: Identidade Territorial. Movimentos Sociais. Blog "Eu na floresta".

\section{CONSIDERAÇÕES INICIAIS}

Fazem parte dos objetivos do presente trabalho a discussão sobre questões de identidade territorial e, por conseguinte, os movimentos sociais que giram em torno dela, apontados nos textos mais recentes do blog Eu na floresta: quem são e como vivem os povos da Amazônia ${ }^{2}$, escrito pela jornalista Maria Fernanda Ribeiro. A discussão é motivada a partir de leituras e questões levantadas na disciplina Linguagem, Fronteira e Interculturalidade, ministrada pelos professores doutores Maria de Jesus Morais e Elder Andrade de Paula, em 2019, no curso de mestrado do Programa de Pós-Graduação em Letras: Linguagem e Identidade - PPGLI, da Universidade Federal do Acre - UFAC.

A motivação para a escolha do tema e do objeto de pesquisa para o presente trabalho se deu a partir de estudos prévios que envolvem o blog Eu na floresta com reflexões sobre representação e imaginário a respeito da Amazônia brasileira. Foram os anos de pesquisa durante a graduação sobre jornalismo ambiental e, mais recentemente, sobre questões de representação e imaginário me possibilitaram enxergar no blog uma oportunidade de estudo relevante. Assim, foi elaborado o trabalho monográfico "Quem são e como vivem os povos da Amazônia": representação e imaginário no blog "Eu na floresta", defendido em 2017 no curso de jornalismo da UFAC e, em seguida, a construção do projeto de pesquisa Onde vivem os "guardiões da floresta": representação e imaginário no blog "Eu na floresta", submetido para o mestrado do PPGLI, também da UFAC.

1 Instituição: Universidade Federal do Acre, Orcid: https://orcid.org/0000-0002-7796-4743, E-mail: karolinioliveira@gmail.com 2 Disponível em: http://sustentabilidade.estadao.com.br/blogs/eu-na-floresta/. 
Já no mestrado, muitas possibilidades de discussão surgiram para essa mesma temática de pesquisa com a disciplina Linguagem, Fronteira e Interculturalidade. De modo algum essas possibilidades facilitaram a escolha da abordagem para o trabalho em questão, uma vez que, além dos assuntos e autores discutidos em sala de aula, os mais diferentes temas, grupos e etnias, cidades e estados foram, e continuam sendo, abordados no blog Eu na floresta, ampliando as abordagens para a temática em questão. Afinal, a proposta da jornalista para o blog inclui falar sobre povos dos nove estados que compõem a Amazônia Legal brasileira ${ }^{3}$.

Assim, as possibilidades de reflexão poderiam focar nos diferentes personagens brasileiros, como indígenas, ribeirinhos e mulheres amazônicas, por exemplo, ou problematizar quem são "os guardiões da floresta" nas publicações do blog, como também seria tema relevante de discussão o sofrimento de mulheres, moradoras de reservas extrativistas, que sofreram abusos e violências de seus companheiros e outros homens nessas comunidades.

De uma outra perspectiva, a Amazônia acreana renderia um trabalho intenso nas questões de movimentos sociais. Em números mais gerais, entre julho de 2016 e o início de agosto de 2019, foram publicados 66 textos no blog. Desse total, 32 textos abordavam exclusivamente, ou de forma parcial, a região acreana ou personagens acreanos. É notório o destaque acreano no blog quando comparado com outros veículos de comunicação a nível nacional. Dessa forma, quase metade das notícias publicadas no sítio tratam da Amazônia acreana ou das pessoas que vivem aqui.

Apesar de ser um número significativo, seria descabido abordar toda essa quantidade de informação, tanto sobre o Acre quanto sobre outras localidades destacadas nos textos de Maria Fernanda, em um único artigo. Dessa forma, levando em consideração essa nova perspectiva que é o olhar a partir da geografia para o blog Eu na floresta, enquanto temática de pesquisa, optou-se por fazer uma breve discussão sobre questões de identidade territorial e sobre os movimentos sociais que giram em torno da Amazônia brasileira, apontados no blog. A discussão se baseia a partir de temas e autores discutidos na disciplina Linguagem, Fronteira e Interculturalidade. Assim, foram selecionados os cinco primeiros textos publicados em 2019, com variados temas, incluindo textos que abordam acreanos, para correlação com alguns dos autores estudados e discutidos em sala de aula.

Sobre o referencial teórico, foram pontuados alguns dos autores estudados na disciplina a fim de melhor discutir o tema. Dessa forma, a presente pesquisa se fundamenta fortemente em conceitos explanados por Rogério Haesbaert (2007;2008) com reflexões sobre as questões de identidade territorial, territorialidade, multiterritorialidade, entre outros aspectos que envolvem o tema e uma breve discussão com Pablo Ortiz Tirado (2006), com estudos sobre conflitos e interculturalidade no centro-sul amazônico, e Maria Angela Comegna (2011), sobre conflitos ambientais e movimentos sociais na Amazônia boliviana.

A partir daí, o trabalho ficou divido da seguinte maneira: na primeira parte é feita uma discussão sobre identidade, território, seguido de uma discussão sobre movimentos sociais em diferentes contextos e, na segunda parte, é feita uma correlação desses temas com os assuntos abordados nos textos do blog Eu na floresta: quem são e como vivem os povos da Amazônia.

3 Acre, Amapá, Amazonas, Pará, Rondônia, Roraima, Tocantins e parte dos estados de Mato Grosso e Maranhão. 


\section{ESPAÇO TERRITORIAL: UMA PERSPECTIVA GEOGRÁFICA INTEGRADA}

A princípio, acreditava-se que a questão da identidade, da cultura e do território seria assunto para diferentes campos de estudos, alocados principalmente em áreas como as ciências sociais, antropologia e sociologia. Isso ocorreu devido estudos prévios durante a graduação que explicavam a presença desses conceitos no mundo das ideias, no mundo simbólico, da representação, como aqueles tratados em Stuart Hall (2016), por exemplo. Quando a disciplina Linguagem, Fronteira e Interculturalidade apresentou uma perspectiva da geografia para esses conceitos, com leituras de Rogério Haesbaert (2007; 2008), Pablo Ortiz Tirado (2006), entre outros, ficou evidente o quão complexo poderia ser trabalhar com as noções de identidade, cultura e território.

Apesar de ser um tema complexo, Haesbaert $(2007 ; 2008)$ deixa claro que buscou também por autores fora da área da geografia para melhor compreender como eram tidas as noções de território, a partir dos conceitos e movimentos relacionados a "desterritorialização" e, ainda, questões da identidade, relações de poder, inclusão e exclusão, relacionando os estudos de autores como Stuart Hall (1996) e Pierre Bourdieu (1989), entre outros.

Além de Haesbaert (2007; 2008), o autor Pablo Ortiz Tirado (2006), nas suas reflexões sobre conflitos e interculturalidade no centro sul amazônico, também coloca em discussão as mudanças e as novas reflexões que ocorreram na geografia nos últimos anos. Tirado explica que, até o início do século XX, os geógrafos deixavam de lado questões fundamentais sobre o espaço e o trabalhavam na geografia como "contenedor de paisajes o de objetos em interacción" (TIRADO, 2006, p.135), como que unicamente relacionado a natureza, sem uma reflexão mais aprofundada sobre o assunto. Segundo o autor, a noção de espaço mais abrangente nas discussões raciais e espaciais, como meio de construção de significados e intercâmbio de símbolos, estereótipos e de movimentos sociais, foi difícil de ser reconhecida no ramo da geografia.

Uma das dificuldades para uma maior compreensão do espaço na geografia, segundo Tirado, é a manutenção metodológica de cientistas dessa área de estudo e de outras que utilizam dados sobre o espaço de forma objetiva e absoluta em suas pesquisas. Porém, é esse discurso, segundo o autor, que finda por "desnaturalizar" o espaço, "pues assume que el espacio no es un ente natural, sino um subproducto social del modo de produción, y que su comprensión solo es posible a partir de uma geo-historia (TIRADO, 2006, p.136). O autor deixa claro ainda que foi uma revolução espacial que produziu um dualismo entre os conceitos de espaço e ambiente, "irónicamente cuando los problemas ambientales ganaban importância (MIRES, 1992)" (TIRADO, 2006, p.135).

Haesbaert (2007) também vai nessa linha de pensamento ao escrever sobre um "tempo-espacial" que fornece referenciais tanto geográficos quanto históricos, portanto, geo-histórico, em que a união de ambas as disciplinas possibilita um olhar mais apurado sobre as questões espaciais. Por conseguinte, ambos os autores, Haesbaert e Tirado, compreendem ainda a complexidade de discussão do espaço tanto no mundo material como no mundo simbólico e, a partir daí, uma abordagem mais integradora sobre o assunto.

Essa perspectiva integradora na geografia é defendida a partir da ideia de que o espaço "em sua dimensão material, não é apenas um 'instrumento de manipulação' no livre jogo da 'invenção' identitária, mas um referencial que [...] passa a interferir na própria intensidade 
e longevidade da dinâmica identitária" (HAESBAERT, 2007, p.45). Isso ocorre porque as relações com o espaço estão diretamente ligadas com a construção das identidades, tanto individuais como de grupos sociais e, em determinado momento, também influenciam em movimentos organizados por grupos sociais.

Além disso, Haesbaert defende uma abordagem cultural integradora na geografia, independentemente dos diferentes conceitos que se podem relacionar ao termo "cultura". Ele escreve: “'toda Geografia é Geografia Cultural', na medida em que não há espaço produzido que não o seja através da cultura dos grupos que o constituem" (HAESBAERT, 2008, p.396), e isso ocorre tanto em um sentido mais amplo, nas relações com a natureza, quanto em um sentido mais estrito, relacionado ao mundo das significações, ao mundo simbólico. Assim, essas relações são debatidas tanto no meio cultural, como também são expandidas para o campo político, econômico e, ainda, na dimensão da própria natureza. O autor complementa:

Embora a princípio coubesse ao geógrafo "manter os pés no chão" e enfatizar sempre a dimensão material do território, a realidade contemporânea, dominada pelo mundo das imagens e das representações, acabou trazendo para o próprio âmbito das proposições geográficas uma visão "mais idealista" de território (HAESBAERT, 2007, p.39).

Assim, entende-se como imprescindível uma abordagem ampla e integradora nas discussões sobre o espaço, pois, a partir de uma discussão mais aprofundada, é possível chegar a uma melhor compreensão sobre o assunto na contemporaneidade. Uma compreensão necessária, uma vez que atores importantes buscam participar, ou ainda se impor, na construção daquilo que Haesbaert (2007) chama de "identidades territoriais", como é o caso do Estado-nação.

No largo debate proposto pelos autores, o Estado-nação vai aparecer na maioria das vezes impondo-se sobre as identidades e os espaços em diferentes países e diferentes contextos. Algumas das ações do Estado sob as questões identitárias e espaciais se dão de forma semelhante em algumas localidades e, embora em outros locais as ações dessa entidade sejam concebidas de forma diferenciada, essas ações sempre vão nos instigar a discutir como são concebidas e elaboradas as questões de identidade e espaço. E, é nesse ponto que essas questões não só podem, como devem, ser trabalhadas a partir da visão integradora proposta pelos autores.

Dessa forma, os próximos tópicos foram elaborados de forma a ampliar o debate sobre conceitos de identidade, espaço, território, territorialidade, desterritorialidade, multiterritorialidade, identidades territoriais, culturas híbridas e movimentos sociais e, posteriormente, as relações desses conceitos com os textos publicados no blog Eu na floresta.

\section{IDENTIDADE, CULTURA E TERRITÓRIO: ALGUNS CONCEITOS}

Já vimos brevemente o quanto se têm defendido uma perspectiva mais integradora sobre o espaço. Desse ponto em diante, a maior parte dos conceitos trabalhados extrapolam uma visão única e limitada sobre identidade, cultura e território. Para Haesbaert (2007), por exemplo, falar sobre esses conceitos é sempre associá-los com outros, considerando-os não só como indissociáveis, mas como constituintes um do outro. 
O autor começa a explicitar essa ideia a partir dos conceitos de território e cultura, ou ainda, território e identidade, como termos compreendidos por seu contraste, mas também como diferentes que se complementam. Nas palavras do autor: "o conceito de cultura surge a partir de seu contraste ou relação com o conceito de 'natureza', assim como o conceito de identidade aparece sobretudo contrastado com ou em relação ao conceito de 'diferença'" (HAESBAERT, 2007, p.35).

Sobre essa relação identidade e diferença, Haesbaert pontua que é a partir das relações de alteridade que a identidade é possível de ser construída, por meio da relação de identificação e diferenciação com o outro. Apesar desse entendimento, o autor deixa claro que seu estudo está voltado mais para o envolvimento de grupos sociais, como questões de identidade nacional e regional, do que para questões de identidade individual em si. Ainda assim, o autor não ignora esses últimos. Isso acontece porque no mundo de "hibridismos", de identidades múltiplas, em que vivemos, é inevitável trabalhar mais "com intersecções e ambivalências do que com fronteiras ou limites claramente definidos" (HAESBAERT, 2007, p.37).

O território, por sua vez, é visto além do espaço geográfico em si, ele é visto em uma dimensão política, por vezes também é vinculada às relações de poder, dentro das diferentes formas com que esse poder pode se manifestar. O território, segundo Haesbaert, "é construído no jogo entre material e imaterial, funcional e simbólico" (HAESBAERT, 2007, p.37). Dessa forma, território carrega a "complexidade com que se constroem essas relações de poder [...] estendendo-se do poder mais visível e 'material' das instituições formalizadas ao poder 'invisível' e simbólico do imaginário e das representações dos diferentes grupos culturais" (HAESBAERT, 2007, p.37).

Seguindo essa linha de raciocínio, o autor explica que "não há território sem algum tipo de identificação e valoração simbólica (positiva ou negativa) do espaço pelos seus habitantes" (HAESBAERT, 1999, p. 172 apud HAESBAERT, 2007, p.38). É importante destacar aqui que essa identificação e valoração simbólica não ocorre somente pelos habitantes de determinado território, mas ainda, pelo "outro" que, em geral, marcam esse lugar a partir de uma visão etnocêntrica, que classifica nós e aos outros, como o próprio Haesbaert complementa:

\footnotetext{
Se identificar(-se) é também, de alguma forma, classificar, estas classificações com que re-significamos o mundo, nós e os outros, inclusive através dos territórios, são objetos de intensas disputas entre aqueles que têm o poder de formular e mesmo de fixar estas classificações (HAESBAERT, 2007, p.37).
}

Citando Derrida, Haesbaert (2007) reforça a relação de contraste entre os conceitos em que estes, em relação com aqueles, acabam por redefinir um ao outro, em um jogo de re-significação que está sempre em aberto. Essas re-significações, ou mais especificamente nos estudos do autor, re-identificações, por estarem sempre ligadas com relações de poder, findam por estar "sujeitas aos mais diversos jogos, ora mais impositivos, ora mais abertos, que este poder implica dentro de uma sociedade profundamente desigual e marcada por processos de dominação" (HAESBAERT, 2007, p.37).

A partir daí, destacam-se as questões de poder e dominação sobre as identidades e sobre os territórios. Em geral, através da história, essas relações se dão de forma etnocêntrica em que determinado grupo, ao entender-se melhor ou superior ao outro, nomeia, faz classificações que vão marcar profundamente a forma de ver e tratar um grupo, um lugar, uma região. 
E o processo de descolonizar esses pensamentos, de ressignificar as narrativas, não é uma tarefa fácil de ser realizada.

\section{TERRITÓRIO E TERRITORIALIDADE}

Baseando-se em um trabalho de Bonnemaison sobre a sociedade de Tanna, no arquipélago de Vanuatu, Haesbaert (2007) explica que a territorialidade funciona, na dimensão simbólica, como uma "ideologia de território". Essa ideologia não implica em uma efetivação do território, mas em uma identificação com ele. E, é isso o que ocorre com os moradores de Tuva, apontados por Haesbaert no estudo de Bonnemaison. Assim, todos os conflitos nessa comunidade, recentes ou não, são moldados por essa ideologia de território "que remonta aos mitos sobre a criação do povo local" (HAESBAERT, 2007, p.40).

A territorialidade então, nessa dimensão simbólica, é usada como argumento para a construção do território, e este último se torna ainda mais eficaz no seu papel de construção da identidade (HAESBAERT, 2007). Assim, a territorialidade, "enquanto 'imagem' ou símbolo de um território, efetivamente existe e pode inserir-se eficazmente como uma estratégia político-cultural, mesmo que o território ao qual se refira não esteja materialmente manifestado (HAESBAERT, 2007, p.40 e 41).

Assim, o poder, no sentido simbólico, precisa ser considerado nas concepções de território, uma vez que "pode ser concebido a partir da imbricação de múltiplas relações de poder, do poder mais material das relações econômico-políticas ao poder mais simbólico das relações de ordem mais estritamente cultural" (HAESBAERT, 2007, p.42). Em suma, as questões de território e territorialidade, além de ter relações diretas com a construção das identidades, também terão conotações políticas e econômicas, o que implica ainda um embate nas relações de poder.

\section{DESTERRITORIALIZAÇÃO E MULTITERRITORIALIDADE}

Após discutir sobre a território e territorialidade, é preciso discutir aqui uma breve compreensão sobre a desterritorialidade. Para Haesbaert (2007), esse termo tem sido abordado de forma incorreta por muitos estudiosos. No geral, o autor explica que a desterritorialidade tem sido explicada apenas como um processo de ir e vir entre territórios, que supostamente causa uma "desterritorialização" desses grupos que se movimentaram, o que para o autor é uma visão simplista da mobilidade de grupos sociais. Assim, o autor propõe que, ao invés de se falar em desterritorialidade, deveria se falar de uma "multiterritorialidade", como entenderemos melhor a seguir.

Segundo Haesbaert, há uma crescente mobilidade em diferentes setores da sociedade que "faz com que a identidade seja construída também, de forma crescente, no e com o movimento. Assim, os próprios referenciais espaciais de identidade podem estar vinculados ao movimento, a "espaços em movimento"" (HAESBAERT, 2007, p.46 e 47), e não só mais ligados à um único espaço territorial. Dessa forma, há a possibilidade de se construir identificações territoriais nessas mobilidades ou com elas.

A partir dessa perspectiva, de acordo com o autor considera um equívoco pensar que esses processos de mobilidade se configuram como uma "desterritorialização". Na verdade, o que acontece para o autor é uma construção identitária multiterritorial, híbrida, e que deve ser mais amplamente discutida. O autor escreve: "o mais comum é que as pessoas e os grupos 
sociais desenvolvam [...] vínculos identitários com mais de um território ao mesmo tempo, ou com territórios que em si mesmos manifestam características muito mais instáveis, múltiplas e/ou híbridas" (HAESBAERT, 2007, p.49).

Essa multiterritorialidade pode ser compreendida também como uma reterritorialização complexa, rizomática, isto é, que permite ter acesso ou se conectar à vários territórios, o que pode acontecer por meio de uma "mobilidade concreta", com o deslocamento físico em si, ou pode ser dar através do mundo virtual, "no sentido de acionar diferentes territorialidades mesmo sem deslocamento físico, como nas novas experiências espaço-temporais proporcionadas pelo chamado ciberespaço" (HAESBAERT, 2004, p.343 e 344 apud HAESBAERT, 2007, p.49). Assim, há a impossibilidade de insistir na compreensão de um mundo "totalizante" ao qual se tentava fazer anteriormente.

Apesar dessa perspectiva da multiterritorialidade ter aberto muitas possibilidades na construção das identidades territoriais, ela também pode ser acompanhada de algumas implicações porque, ao passo que a muliterritorialidade possibilita a existência de identidades territoriais múltiplas, as identidades são formadas por grupos que querem reconhecimento e grupos que visam a dominação. Dessa forma, o território finda por tornar possível uma "articulação de poderes simbólicos de múltiplas faces, que ora reforçam a segregação e o fechamento - naquilo que denominamos 'reclusão territorial', e ora potencializam uma dinâmica de convívio ou de ativação de múltiplas identidades" (HAESBAERT, 2007, p. 50). Há assim, uma abordagem essencialista nas questões de identidade territorial, onde são difundidas noções essencializadas nas lutas por reconhecimento.

Essa essencialização, ou re-essencialização identitária, ao contrapor esse termo com a noção de multiterritorialidade, é "claramente evidenciada na proliferação de fundamentalismos nacionalistas, étnicos e religiosos" (HAESBAERT, 2007, p.51), algo que funciona como um pretenso "retorno às origens".

\section{IDENTIDADE TERRITORIAL E MOVIMENTOS SOCIAIS}

A identidade territorial que tanto tem se discutido funciona aqui como um casamento em que os povos de uma comunidade criam ou reforçam laços com o território. A identidade territorial é, dessa forma, o meio pelo qual são, não apenas escolhidos, mas reconstruídos os "espaços e tempos, geografias e histórias para moldar uma identidade, de modo que os habitantes de um determinado território se reconhecem, de alguma forma, como participantes de um espaço e de uma sociedade comuns" (HAESBAERT, 2007, p.43).

Esse sentimento de pertencimento é o que vai motivar as diferentes ações sociais de um grupo, tais como as lutas por reconhecimento e reinvindicação de direitos. Isso ocorre porque, segundo Lévi-Strauss, "a luta para afirmar as diferentes identidades tem causas e consequências materiais" (STRAUSS apud HAESBAERT, 2007, p.43). E é a partir dessa luta que as identidades territoriais se efetivam, pois é aí que um referente espacial vem a se tornar um elemento significativo tanto para a identificação como para a ação política de um grupo. Afinal de contas, a identidade territorial é "um espaço em que a apropriação é vista em primeiro lugar a partir da filiação territorial, e onde tal filiação inclui o potencial de ser ativada, em diferentes momentos, como instrumentos de reinvindicação política" (HAESBAERT, 2007, p.45). 
É central o papel da identidade territorial nas questões e reinvindicações de grupos sociais como associação de moradores de bairros, dada como exemplo por Haesbaert (2007), onde esses grupos se mobilizam para melhorias na comunidade. Porém, segundo o autor, os limites para a identificação territorial podem ser ainda mais abrangentes alcançando comunidades outras como municípios, regiões e Estados-nações.

Segundo Haesbaert (2007), a identidade territorial mais difundida é a identidade nacional que, de certa forma, tenta homogeneizar diferentes grupos sob a justificativa de um território único, uma nação. Essa situação é acompanhada, por sua vez, pela luta de diferentes grupos que discordam e/ou não apoiam uma visão única sobre si, entre outras questões. Um exemplo disso são as lutas dos povos Kichwa, Zápara, e Achuar de Pastaza, na Amazônia equatoriana. De acordo com Tirado (2006), a luta desses povos por reconhecimento e autonomia tem ido de frente contra a tentativa das elites de manter e estender uma hegemonia não só sobre estes povos, mas sobre os territórios reclamados pelo Estado. Os movimentos desses grupos indígenas, segundo Tirado, representam uma ameaça ao Estado, principalmente quando este último é integrado por um grupo que exclui ou subordina outros grupos que são diferentes tanto no aspecto cultural como em termos de etnia.

O capitalismo também tem tido forte participação nas questões do território pois agregou formas de domínio territorial a partir da ampliação de comércios internacionais (HAESBAERT, 2007; TIRADO, 2006). Segundo Tirado, na Amazônia o capitalismo tem influenciado na "ampliación de la frontera extractiva de recursos renovables, y en la delegación cada vez más fuerte al capital transnacional, de las responsabilidades de ordenamiento del territorio" (TIRADO, 2006, p. 134). Um dos exemplos disso é o estudo de Maria Angela Comegna (2011) sobre Conflitos ambientais e movimentos sociais na Amazônia boliviana.

No estudo de Comegna (2011), a Iniciativa para a Integração da Infra-Estrutura Regional Sul-Americana (IIRSA), tinha como objetivo na época a construção de um complexo hidrelétrico no rio Madeira, que fica em um dos principais eixos da iniciativa que é o eixo Brasil-Peru-Bolívia. Esse eixo é considerado importante tanto pela integração física entre os países, também por causa da integração comunicacional e, por fim, pela integração energética.

A discussão da autora se dá a partir de movimentos sociais organizados por grupos indígenas bolivianos na chamada Confederación de Pueblos Indígenas de Bolivia (Cidob), onde esses grupos objetivam promover um desenvolvimento sustentável ${ }^{4}$ e ainda a manutenção da identidade cultural de seus povos. Porém, o que ocorreu foi que o projeto da IIRSA causou inúmeros conflitos entre as comunidades locais, indígenas e migrantes que procuravam por trabalho nessas construções hidrelétricas, para citar apenas alguns dos problemas ocasionados. Isso se deu porque, os objetivos da IIRSA estão voltados somente para uma integração física, e não uma integração de povos e de diferentes culturas.

Os exemplos citados, tanto dos estudos da Comegna como os estudos de Tirado, representam uma pequena parcela das mobilizações que têm ocorrido em diferentes países da América Latina. São movimentos organizados por grupos sociais, principalmente indígenas, na luta por reconhecimento e respeito às suas identidades territoriais e que têm posto a Amazônia no centro de muitas dessas discussões. Assim, de forma a dar uma continuidade nas

4 Em outros estudos há uma larga discussão sobre o desenvolvimento sustentável, como na abordagem do professor Elder Andrade de Paula no livro Desenvolvimento insustentável na Amazônia ocidental (2005). É um debate, sem dúvida, imprescindível, mas que, por fins de espaço, serão abordados em outro momento. 
reflexões levantadas até aqui, o próximo tópico procura compreender como as questões de identidade territorial e movimentos sociais se dão no blog Eu na floresta.

\section{IDENTIDADE TERRITORIAL E MOVIMENTOS SOCIAIS NO BLOG EU NA FLORESTA: QUEM SÃO E COMO VIVEM OS POVOS DA AMAZÔNIA}

No segundo semestre de 2016, mais precisamente no mês de julho daquele ano, a jornalista Maria Fernanda Ribeiro deu início às inúmeras viagens que ela faria para a Amazônia brasileira a fim de conhecer os povos da Amazônia e publicar relatos sobre eles no blog Eu na floresta: quem são e como vivem os povos da Amazônia. Online desde então na editoria de sustentabilidade do jornal Estadão, o blog já foi palco de discussão de diversos temas sobre a região amazônica brasileira, abrangendo desde questões indígenas, como questões ambientais e até questões pessoais da jornalista.

Como o blog possui temáticas interessantes para diferentes abordagens de estudo, foi proposto para o presente trabalho fazer uma breve discussão sobre identidade territorial e movimentos sociais nos textos mais recentes do blog. A discussão sobre a temática se dá a partir dos assuntos estudados na disciplina Linguagem, Fronteira e interculturalidade, e é fundamentado, principalmente, nas leituras de autores como Rogério Haesbaert (2007; 2008) e Pablo Ortiz Tirado (2006). Assim, no intuito de fazer uma abordagem inédita sobre o assunto, os textos separados para correlação com os estudos da disciplina são os primeiros cinco publicados no blog Eu na floresta, em 2019.

Os títulos dos textos são: A luta dos povos indígenas é de todos nós. Ou ao menos deveria ser, publicado em 04 de fevereiro; Povo Kìsêdjê, do Xingu, planta pequi em área degradada e entrega produção recorde, publicado em 11 de fevereiro; Série retrata a luta de três lideranças indígenas reconhecidas pela ONU e ameaças de morte, publicado em 19 de fevereiro; Índios Panará denunciam negligência em atendimento a crianças no MT, publicado em 22 de fevereiro; e Povo Pankararu faz financiamento coletivo para encontro anual em São Paulo, publicado em 19 de março.

O primeiro texto publicado pela jornalista em 2019 foi A luta dos povos indígenas é de todos nós. Ou ao menos deveria ser, publicado em 04 de fevereiro. O texto trata da manifestação popular de indígenas e não indígenas contra ao que foi denominado no texto como "políticas anti-indiginistas" do governo Bolsonaro, realizado em vários pontos do país, no dia 31 de janeiro de 2019.

De acordo com o texto, a manifestação desse dia ocorreu após a divulgação de que a Fundação Nacional do Índio (Funai) seria transferida do Ministério da Justiça para o Ministério da Agricultura. "'Deixar a demarcação de terras com o Ministério da Agricultura é o mesmo que colocar a raposa para tomar conta do galinheiro', diziam os manifestantes" (RIBEIRO, 2019a, online). Aqui já é possível perceber o caráter territorial e de movimento social desses grupos, corroborando os apontamentos de Haesbaert, em que o autor explicita que:

\footnotetext{
A identidade territorial só se efetiva quando um referente espacial se torna elemento central para a identificação e ação política do grupo, um espaço em que a apropriação é vista em primeiro lugar a partir da filiação territorial, e onde tal filiação inclui o potencial de ser ativada, em diferentes momentos, como instrumentos de reinvindicação política (HAESBAERT, 2007, p.45)
} 
A ligação identitária que os povos indígenas do Brasil têm com o território onde vivem é motivo de luta há muitos anos. Como mencionado em outro anteriormente nesse trabalho, é central o papel da identidade territorial nas questões e reinvindicações de grupos sociais. No caso dos indígenas, esse movimento é conhecido desde os processos de colonização do Brasil pela coroa portuguesa e mais especificamente, como apontaremos neste estudo, na Amazônia brasileira com os conflitos gerados durante as expedições de viagem organizadas para o "descobrir" e se "apossar" da terra (OLIVEIRA, 2019). Assim, os movimentos de resistência também fazem parte da construção das identidades territoriais. Um exemplo disso pode ser percebido no trecho a seguir:

Resistir, está aí outro verbo entoado com convicção, seja pelos povos que vivem em contexto urbano ou por aqueles que estão pela floresta. Resistência que não é de hoje, é de séculos. O que muda é a cara do inimigo e sua capacidade de fogo. Não ao genocídio indígena eram as palavras de alguns dos cartazes em punho (RIBEIRO, 2019a, online).

É nesse primeiro texto que vemos como o espaço, o território, é disputado como meio de dominação simbólica em que, tanto o Estado, como as comunidades moradores desses espaços, fazem disputas para poder ter acesso a ele.

Em outro trecho do texto é possível enxergar claramente como as questões sobre identidade estão em discussão nesse meio de comunicação que é o blog Eu na floresta:

Pensei, enquanto caminhava pela manifestação, que engrossar o coro à causa dos povos indígenas não é uma tarefa apenas identitária, é um dever de todo e qualquer cidadão que também deseja ter o seu direito respeitado. Não cabe a nenhum de nós ditar regras de como cada ser deseja viver. Se você integra o time que acredita piamente que índio que é índio não mora na cidade, não usa celular e anda nu por aí, não deixe que o desconhecimento, a ignorância ou o preconceito limite seus pensamentos. Informe-se, leia, pergunte a um índio o que eles desejam. O maior bem que há é a diversidade, a cultura, a arte de cada povo. E essa diversidade é o Brasil, de cabo a rabo. Só não enxerga quem se esconde na coxia e não sai para o espetáculo, seja por medo, preguiça ou desinteresse. Os índios sabem disso e todos nós só temos a ganhar com essa luta, que não é deles, mas de todos nós. (RIBEIRO, 2019a, online, grifo meu).

No trecho acima, a jornalista enfatiza alguns pontos sobre os indígenas como a possibilidade deles de morar na cidade, de usar celular, entre outros. A partir daí, depreende-se que houve uma conexão com outras culturas, dando início à uma multiterritorialidade uma hibridização cultural desses povos, como destacado nos estudos de Haesbaert para o trabalho em questão. Embora a problemática em torno da hibridização das culturas indígenas seja um tema relevante a ser discutido, é um debate com pouca base bibliográfica neste trabalho, ficando, assim, para outro momento.

Outro ponto destacado nesse texto é a presença dos indígenas no mundo virtual, no ciberespaço. O texto destaca a importância desse espaço na luta e nas reinvindicações desses povos por seus direitos: "[...] as fotos publicadas pelos próprios indígenas (sim, caros leitores, índio usa celular e tem perfil no Facebook e publicam stories no Instagram) mostravam que a disposição para que seus direitos sejam garantidos é a ferramenta que usam para lutar" (RIBEIRO, 2019a, online). 
É importante destacar o posicionamento de Haesbaert (2007) sobre o ciberespaço como um meio de fazer conexão entre diversos territórios. No caso das manifestações do dia 31 de janeiro, o mundo virtual serviu tanto para interação e conexão entre diferentes povos como também proporcionou uma mobilidade desses povos para um encontro na luta por seus direitos.

Nos textos de 2019 é possível encontrar diversos sites e páginas na internet onde grupos e comunidades indígenas se fazem presente, como no texto Povo Kĩsêdjê, do Xingu, planta pequi em área degradada e entrega produção recorde, onde é destacado o link da Associação Indígena Kĩsêdjê no Facebook ${ }^{5}$.

Além da promoção do povo Kĩsêdjê no mundo virtual, a jornalista destaca no texto em questão sobre como esse povo transformou uma área degradada, que anteriormente pertencia à um fazendeiro, em uma plantação de pequis. É destacado ainda que o óleo de pequi produzido por essa comunidade tem um selo reconhecido nacionalmente, o Selo Origens Brasil, que é expedido para "produtos de áreas protegidas balizados por relações comerciais éticas, justas e transparentes" (RIBEIRO, 2019b, online). Ainda de acordo com o texto, um membro da comunidade, Winti Kĩsêdjê, garantiu que a "iniciativa foi a única solução [para obter renda] que achamos mais viável e que não agride ninguém, nem o meio ambiente"" (WINTI KĨSÊDJÊ, em entrevista concedida para RIBEIRO, 2019b, online).

Já no texto Série retrata a luta de três lideranças indígenas reconhecidas pela ONU e ameaças de morte, antes de mencionar o foco principal do texto que é falar sobre a série Guerreiros da Floresta, a jornalista deixa claro que pretende manter a divulgação de sites que considera importantes no apoio à questão de diferentes comunidades por onde passa:

\footnotetext{
Expliquei rapidamente em textos anteriores, mas farei novamente para quem não leu, que esse espaço agora será preenchido- já estou fazendo isso na verdade - para também divulgar iniciativas, ideias, propostas, ações e soluções que envolvam os povos da floresta, sejam eles indígenas, quilombolas ou ribeirinhos. A ideia é que as pessoas possam conhecer mais sobre as pessoas que habitam a Amazônia e como elas são impactadas por ações que se auto-intitulam em nome do desenvolvimento e do progresso (RIBEIRO, 2019c, online).
}

A série Guerreiros da Floresta, abordada no texto acima, fala sobre três lideranças indígenas de diferentes estados da Amazônia brasileira, Davi Kopenawa, de Roraima; Almir Suruí, de Rondônia e Ninawa Huni Kuin, do Acre, e sobre a luta promovida por eles "em defesa da sustentabilidade da Amazônia e da herança de seus povos" (RIBEIRO, 2019c, online). De acordo com o texto, a série mostra um pouco da cultura da etnia de cada um desses líderes "abordando suas semelhanças e particularidades de estilo de vida, além da luta por preservação e sobrevivência" (RIBEIRO, 2019c, online). Alguns episódios da série ${ }^{6}$, que foi transmitida em fevereiro no canal Futura, podem ser encontrados atualmente no Youtube. Para ter uma noção do que a séria trata, a jornalista divulgou um link do teaser da série no blog ${ }^{7}$. Mais uma vez pode-se perceber aqui como os diferentes espaços, virtuais e materiais, têm sido utilizados como meio de manifestação de grupos sociais.

5 Disponível em: https://www.facebook.com/AIKisedje/.

6 Disponível em: https://www.youtube.com/watch?v=wpCvd6mQHrY\&list=PLNM2T4DNzmq5spU0aa07ZeaJJKflyMOSb.

7 Disponível em: https://www.youtube.com/watch?v=P4vJgB7i9b0\&feature=youtu.be. 
Mas a luta de muitos desses grupos não é motivada somente pelo direito à terra, como foi mostrado no texto sobre os KĨsêdjê, que conseguiram a demarcação de uma terra que estava tomada por um fazendeiro, e como no caso da série Guerreiros da floresta, que relata um pouco das lutas que indígenas têm passado contra aqueles que procuram invadir suas terras com finalidades econômicas. Questões de saúde também entram em pauta nos movimentos sociais, como mostra o texto Índios Panará denunciam negligência em atendimento a crianças no $M T$. Esse texto trata das reinvindicações dos Paraná por melhorias na saúde infantil do Mato Grosso, principalmente depois que uma criança indígena de um ano de idade morreu devido ao descaso do Hospital Regional de Colíder. Após o ocorrido, a comunidade se reuniu e enviou um documento tanto para a direção do hospital quanto para o Ministério Público do MT, pedindo por melhorias. Segue um trecho do documento divulgado no blog:

[...] Sên morreu [a criança indígena de um ano de idade], até hoje não sabemos o porquê. Ele foi enviado com suspeita de pneumonia em outubro, para morrer dois meses depois, após entrar e sair em vão inúmeras vezes desse hospital", afirmam eles, no documento, onde acrescentam: "Que essa seja a última criança, Panará ou não Panará, indígena ou não indígena, a ser tratada com este descaso (RIBEIRO, 2019d, online).

Além dos movimentos em prol da sua própria comunidade, como temos vistos em outros textos, a comunidade indígena dos Paraná demonstrou lutar por questões que não são só deles, mas que deveria ser um direito de todos.

Já o texto Povo Pankararu faz financiamento coletivo para encontro anual em São Paulo, tem pontos interessantes de discussão. Ocorre que o povo Pankararu, que mantém sua comunidade no espaço urbano da cidade de São Paulo, utilizou o espaço virtual a fim de levantar fundos para realização de uma festa organizada anualmente por eles. A festa, segundo Clarice Pankararu, é para disseminar as tradições da etnia entre os mais jovens que já nasceram na cidade, o que implica em um convite tanto para outras comunidades que vivem em regiões urbanas, quanto para não indígenas que desejam socializar a conhecer mais os costumes dessa comunidade. Ou seja, há aqui uma relação entre culturas, um entrelaçamento de identidades, provavelmente os processos de uma multiterritorialidade em ação (RIBEIRO, 2019e).

O mais curioso sobre os Pankararu é que ocorreu com eles uma espécie de mobilidade, como aquela explicada por Haesbaert (2007). De acordo com o texto, essa mobilização de um espaço para outro começou na década de 1930, quando indígenas dessa comunidade começaram a se deslocar do Nordeste para a região de São Paulo motivados por melhores condições de vida com a construção civil. Atualmente, cerca de 160 famílias da etnia vivem na região do Real Parque, na zona sul de São Paulo.

O caso dos Pankararu é um caso em particular relatado no blog, pois trata da única comunidade mencionada no blog que não está firmada na região amazônica brasileira e que, apesar de estarem alocados em um espaço urbano, uma metrópole como São Paulo, procuram manter e perpetuar, para os mais jovens, as tradições que trouxeram de sua terra natal.

Há, desse modo, um reforço da identidade desse povo que, embora ambientado em outra região que não a sua de origem, luta por promover e manter viva os componentes da identidade que marcam os seus costumes e as suas tradições. 


\section{CONSIDERAÇÕES FINAIS}

Compreender como se dão as relações entre identidade territorial e movimentos sociais não é uma tarefa fácil de ser cumprida. Como explicitado no início do trabalho, os assuntos abordados em sala de aula, como temas sobre identidade e território se mostraram complexos quando se integram autores da geografia com autores de diferentes campos de estudo. Contudo, foi a partir dessas discussões que se tornou possível uma compreensão de como a identidade territorial motiva e dá fôlego, todos os dias, a diferentes movimentos sociais que se levantam em prol desta ou daquela comunidade, ou ainda, de muitas comunidades com interesses em comum, como foi o caso da manifestação de janeiro em que várias etnias se reuniram com o propósito de contrapor as políticas de governo anti-indigenistas do atual governo em diversas regiões do país. Poderíamos citar como exemplo ainda os índios Paraná que reivindicavam melhorias na saúde tanto para crianças da comunidade deles quanto para toda e qualquer criança que precisasse de atendimento.

Com publicações de diferentes temas e em diversos contextos, o blog Eu na floresta revelou, a partir de uma perspectiva geográfica sobre identidade territorial, que diferentes movimentos sociais surgem e ganham notoriedade em diferentes ambientes espaciais, tanto em seus respectivos lugares de estabilidade, como no caso dos Paraná, quanto no caso das diferentes etnias que se reuniram em diversas cidades brasileiras para se manifestar contra as ações políticas anti-indiginistas do atual governo.

Um outro aspecto notado nos textos do blog é a presença de diversas comunidades no ciberespaço em busca de expandir sua cultura, suas tradições e, sobretudo, para convidar a outros para melhor conhecer seus modos de vida e interesses. O ciberespaço também se mostrou estar sendo utilizado pelas comunidades como forma de pedir ajuda, como no caso dos Pankararu, ou para divulgar a relevância de suas lutas, como o caso da série Guerreiros da floresta.

Já no caso do povo Kĩsêdjê, além dessa comunidade ter conseguido que uma terra em posse de um fazendeiro fosse demarcada, eles conseguiram fazer dessa terra um meio de produção útil para a comunidade. Embora o blog não conte como eles conseguiram a demarcação da terra, pode-se deduzir que houve muita luta dessa comunidade para que isso se tornasse possível. Além do mais, a comunidade também mantém uma página na internet para contar um pouco da sua história e interagir com outras comunidades.

Diferente de outros movimentos, como os relatados por Tirado (2006) sobre as comunidades equatorianas, ou aqueles relatados por Comegna (2011) na Amazônia boliviana, em que os movimentos foram organizados principalmente no mundo material, o espaço virtual ganhou mais atenção das comunidades brasileiras no sentido de organização, divulgação e compartilhamento de informações sobre os movimentos sociais e, ainda mais, sobre as comunidades em si, como foi apontado nos textos do blog. Ainda que em outros estudos as interações no ciberespaço tenham sido melhor abordadas, é importante destacar a relevância que esse espaço tem ganhado para esse tipo de movimento e suas organizações.

Todas essas questões apresentadas no blog só reforçam o quanto uma visão jornalística integrada aos estudos da geografia pode contribuir para a compreensão dos movimentos sociais organizados na contemporaneidade. Movimentos sociais esses que estão sempre, de 
alguma forma, ligados à noção de identidade territorial, pois é só a partir dela que Haesbaert (2007) acredita ser possível a organização desses movimentos.

Longe de ser um trabalho finalizado, considera-se que os casos apresentados aqui foram abordados de forma breve e que, sobretudo, merecem e precisam ser amplamente discutidos. É certo que as questões da identidade territorial, os movimentos sociais, e todas as implicações decorrente delas vão ser melhor estudadas e analisadas em estudos posteriores, tanto para uma melhor abordagem sobre cada aspecto mencionado no trabalho quanto sobre aspectos outros que, por muitos motivos e organização do texto, ficaram de fora das discussões neste momento. $\mathrm{O}$ que significa que as questões aqui abordadas são mais do que um novo modo de olhar uma temática de pesquisa, mas são, sobretudo, temas de real relevância e que merecem maior debate na atualidade.

\section{TERRITORIAL IDENTITY AND SOCIAL MOVEMENTS ON THE BLOG "EU NA FLORESTA": A GEOGRAPHICAL PERSPECTIVE}

ABSTRACT: This paper aims to make a brief discussion about the territorial identity and the social movements reproduced in the blog "Eu na floresta: quem são e como vivem os povos da Amazônia". Written by the journalist Maria Fernanda Ribeiro, the blog has been hosted on the Estadão newspaper website since 2016, when the journalist traveled to Acre to begin her journey through the Amazon. The reflections raised were motivated from reading about the topic and the discussions made in the classroom during the discipline "Language, Frontier and Interculturality", in the master's course of the Postgraduate Program: Language and Identity - PPGLI, at the Federal University of Acre - UFAC. Among the authors studied in the discipline, Rogério Haesbaert and Pablo Ortiz Tirado base the work with different concepts of territorial identity and social movements.

KEYWORDS: Territorial Identity. Social movements. Blog "Eu na Floresta".

\section{REFERÊNCIAS BIBLIOGRÁFICAS}

COMEGNA, M. A. Conflitos ambientais e movimentos sociais na Amazônia boliviana. Revista Geográfica de América Central, vol. 2, julio-diciembre, 2011, p. 1-17. Universidad Nacional. Heredia, Costa Rica.

HAESBAERT, R. Hibridismo, mobilidade e multiterritorialidade numa perspectiva geográficocultural integradora. In: Espaços culturais: vivências, imaginações e representações. SERPA, Angelo (organizador). - Salvador: EDUFBA, 2008. p.393-419.

HAESBAERT, R. Identidades territoriais: entre a multiterritorialidade e a reclusão territorial (ou: do hibridismo cultural à essencialização das identidades). In: ARAÚJO, Francisco Guilherme Bandeira de; HAESBAERT, Rogério (organizadores). Identidades e territórios: questões e olhares contemporâneos. Rio de Janeiro: Access, 2007. p.33-56.

OLIVEIRA, K. Representação e imaginário na Amazônia brasileira: um estudo do blog "Eu na floresta". Anais da VIII Semana Acadêmica de Comunicação Social (Seacom) da Universidade Federal do Acre - UFAC, 2019, Rio Branco, AC. Disponível em: https://seacomufac.files.wordpress. com/2019/06/anais-seacom-2019.pdf. Acesso em: 16 de agosto de 2019.

RIBEIRO, M. F. A luta dos povos indígenas é de todos nós. Ou ao menos deveria ser. Blog Eu na floresta: quem são e como vivem os povos da Amazônia, 2019a. Disponível em: https:// sustentabilidade.estadao.com.br/blogs/eu-na-floresta/a-luta-dos-povos-indigenas-e-de-todos-nos-ouao-menos-deveria-ser/. Acesso em: 03 de agosto de 2019.

RIBEIRO, M. F. Povo Kĩsêdjê, do Xingu, planta pequi em área degradada e entrega produção recorde. Blog Eu na floresta: quem são e como vivem os povos da Amazônia, 2019b. Disponível em: https:// sustentabilidade.estadao.com.br/blogs/eu-na-floresta/povo-kisedje-do-xingu-planta-pequi-em-areadegradada-e-entrega-producao-recorde/. Acesso em: 03 de agosto de 2019. 
RIBEIRO, Maria Fernanda. Povo Pankararu faz financiamento coletivo para encontro anual em São Paulo. 2019e. Blog Eu na floresta: quem são e como vivem os povos da Amazônia, Disponível em: https://sustentabilidade.estadao.com.br/blogs/eu-na-floresta/povo-pankararu-faz-financiamentocoletivo-para-encontro-anual-em-sao-paulo/. Acesso em: 03 de agosto de 2019.

RIBEIRO, M. F. Série retrata a luta de três lideranças indígenas reconhecidas pela ONU e ameaças de morte. Blog Eu na floresta: quem são e como vivem os povos da Amazônia, 2019c. Disponível em: https://sustentabilidade.estadao.com.br/blogs/eu-na-floresta/serie-retrata-a-luta-de-tres-liderancasindigenas-reconhecidas-pela-onu-e-ameacas-de-morte/. Acesso em: 03 de agosto de 2019.

RIBEIRO, M. F; BARBA, M. D. Índios Panará denunciam negligência em atendimento a crianças no MT. Blog Eu na floresta: quem são e como vivem os povos da Amazônia, 2019d. Disponível em https://sustentabilidade.estadao.com.br/blogs/eu-na-floresta/indios-panara-denunciamnegligencia-em-atendimento-a-criancas-no-mt/. Acesso em: 03 de agosto de 2019.

TIRADO, P. O. Tres notas sobre conflictos e interculturalidad en el centro sur de la Amazonia. Universitas: Revista de Ciencias Sociales y Humanas. Universidad Politécnica Salesiana del Ecuador, 2006. Disponível em: https://universitas.ups.edu.ec/index.php/universitas/article/view/4.2004.04. Acesso em: 14 de agosto de 2019.

Data submissão: 08/06/2020

Data aprovação:23/06/2020 